\title{
Volvulus Acute of the Colonist Sigmoid to Mopti: Diagnostic and Therapeutic Aspects
}

\author{
Bréhima Bengaly¹, Abdoulaye Kantée, ${ }^{2 *}$, Drissa Ouattara1, Bréhima Coulibaly ${ }^{1}$, Drissa Traoré ${ }^{2}$, \\ Birama Togola1, Babou Ba3 ${ }^{3}$, Souleymane Sanogo', Siaka Diallo1, Djibril Traoré2, \\ Moustapha Issa Magané ${ }^{4}$, Mariam Daou $^{5}$, Nouhoum Ongoïba ${ }^{1}$
}

\author{
${ }^{1}$ Service of Surgery B, CHU Point G, Bamako, Mali \\ ${ }^{2}$ Service of General Surgery, Sominé Dolo of Mopti Hospital, Mali \\ ${ }^{3}$ Laboratory of Anatomy of the Faculty of Medicine and Odontostomatology, Bamako, Mali \\ ${ }^{4}$ Service of Anesthesia and Resuscitation, CHU Gabriel Touré, Bamako, Mali \\ ${ }^{5}$ Service of Neurology, CHU Gabriel Touré, Bamako, Mali \\ Email: *kanteim@yahoo.fr
}

How to cite this paper: Bengaly, B., Kanté, A., Ouattara, D., Coulibaly, B., Traoré, D., Togola, B., Ba, B., Sanogo, S., Diallo, S., Traoré, D., Magané, M.I., Daou, M. and Ongoiba, N. (2018) Volvulus Acute of the Colonist Sigmoid to Mopti: Diagnostic and Therapeutic Aspects. Surgical Science, 9, 446-453.

https://doi.org/10.4236/ss.2018.911050

Received: August 31, 2018

Accepted: October 15, 2018

Published: November 29, 2018

Copyright ( $) 2018$ by authors and Scientific Research Publishing Inc. This work is licensed under the Creative Commons Attribution International License (CC BY 4.0).

http://creativecommons.org/licenses/by/4.0/

\begin{abstract}
In 7 years, we brought together 100 cases of volvulus of the colon sigmoid to the hospital Sominé Dolo of Mopti among which the handle volvule was found without necrosis in 66 cases and necrosis 34 cases. Seventy-six patients benefited from a sigmoidectomy followed by a colorectal anatomize at a time, twenty one patients of an intervention of Hartmann. A surgical distortion was realized at 3 patients. All the patients operated by these last two techniques had a restoring of the digestive continuity for an average deadline of 90 days. The post-operative complications consisted of 11 cases of parietal suppuration and a case of evisceration. The average duration of follow-up was of 210 days. The post-operative mortality was $14 \%$. It was about a state of toxic shock with visceral multi-failure $(\mathrm{n}=13)$, and of a pulmonary embolism $(\mathrm{n}=$ 1). The treatment of the volvulus requires a fast diagnostic and therapeutic coverage. The best treatment consists of a resection of the sigmoid as a matter of urgency followed by an immediate anastomosis if the following conditions are carried achieved: state general voucher, experimented surgeon and if the resuscitation meadow, per and post-operative can be assured.
\end{abstract}

\section{Keywords}

Pelvic Colonist, Volvulus, Treatment, Mopti, Mali

\section{Introduction}

The volvulus of the sigmoid (VS) is a medical and chirurgical urgency. It realizes 
a board of low colonic occlusion by strangulation which commits the prognosis for survival because it can pull a colonic necrosis with the risk of a stercoral peritonitis. It is a relatively rare affection representative 2 in $4 \%$ of the acute intestinal obstructions [1], it is favored by the existence of a dolicho sigmoid with a long meso on narrow base, retracted by the fibrosis [2]. The diagnosis of volvulus of the sigmoid is most of the time easy but the treatment is subject to controversy. Several surgical techniques were proposed, going pexies and meso-sigmoidoplasties in the colectomy at one or two times [3].

The laparoscopic surgery was recently proposed in the treatment of volvulus of the sigmoid [4]. As a matter of urgency, the best treatment consists in our context where the endoscopic devolvulation is not possible, in a resection of the sigmoid followed by an immediate anastomosis if the following conditions are carried achieved: state general voucher, experimented surgeon and if the resuscitation meadow, per and post-operative can be assured [5]. The purpose of this work is to analyze the modalities of the coverage of the volvulus of the sigmoid, and to propose a therapeutic attitude.

\section{Materials and Methods}

It was about a retrospective study of 100 cases of volvulus of the sigmoid, taken care in the service of general surgery at the regional hospital of Mopti in Mali from January, 2005 till December, 2011.

All the patients operated for volvulus were included in this study. The patients operated for other surgical pathologies were not included.

The data collection based itself on the study of the files of the patients, specifying the clinical presentation, the realized complementary examinations and on the operating reports and the data of the follow-up operating comment.

The studied variables were: the sociodemographic characteristics, the clinical signs and paracliniques, the operating techniques, and the post-operative suites.

These data were seized and analyzed on the software Ear Information (version 6). The test of Khi2 and Student were used to compare our results to those of the other authors. The threshold of meaning was fixed to 0.05 .

\section{Results}

Hundred patients presenting a volvulus of the sigmoid were hospitalized in our service during a period of 6 years. It is about 94 men and 6 women. The average age was of 41.5 years with extremes of 14 years and 88 years.

A chronic constipation was noted at 84 sick (84\%). Four patients had histories of HTA and a sick person of Diabetes (Table 1).

The average deadline between the beginning of the symptomatology and the consultation was of 69.4 hours with extremes of 24 and 120 hours. The symptoms which were observed are the ones of a colonic occlusion. The clinical examination found besides the occlusive syndrome, the peritoneal syndrome at 34 patients and the set of three of Von Wahl at 87 patients. The radiography of the 
belly without preparation (Figure 1) allowed evoking the diagnosis of VS in 65 cases.

The diagnosis of VS was put in preoperative at 65 patients that are $65 \%$ of the cases (Table 2). The diagnosis was made preoperative in 35 cases there.

All the patients were operated as a matter of urgency considering the complete character of the occlusion. The way at first used was a median laparotomy in $100 \%$ of the cases.

Seventy six patients benefited from a sigmoidectomy followed by a colorectal anatomize at a time. The operation of Hartmann was realized in 21 cases (21\%). The digestive continuity was restored for an average deadline of 90 days. The surgical distortion was realized at 3 patients (3\%) (Figure 2).

The post-operative complications consisted of 11 cases of parietal suppuration and a case of evisceration. The average duration of follow-up was of 210 days. The post-operative mortality was $14 \%$. It was a question in 13 cases of a state of toxic shock with visceral multi-failure, and in 1 case of a pulmonary embolism (Table 3).

\section{Discussion}

The volvulus of the sigmoid is the most frequent cause of the colonic occlusions by strangulation. It represents $2 \%$ to $4 \%$ of the acute intestinal obstructions [1] [2]. The majority of the patients who presenting one VS, have disorders of the colonic motricity [6] [7], as gives evidence of it the constipation and the abdominal meteorism in their histories. Certain authors consider the volvulus of the sigmoid as being a form of expression of the disease of Hirschsprung [7]. This explains the frequent association of a dolichomegacolon and a second offense of the volvulus after sigmoïdectomie [2]. Other factors were brought back, such as the constipation chronicles, a high-fiber diet food, the pregnancy or a pelvic tumor [8].

Table 1. Patients.

\begin{tabular}{cc}
\hline Average age of the patients & 41.5 years \\
\hline Sex-ratio & $15.67(\mathrm{M}=94 ; \mathrm{F}=6)$ \\
Constipation chronicles & $\mathrm{n}=84(84 \%)$ \\
Diabetes & $\mathrm{n}=1(1 \%)$ \\
HTA & $\mathrm{n}=1(1 \%)$ \\
\hline
\end{tabular}

Table 2. Clinical examination.

\begin{tabular}{cc}
\hline Average deadline of evolution of the symptomatology & 69.36 hours \\
\hline occlusive syndrome & $\mathrm{n}=76(76 \%)$ \\
syndrome peritoneal & $\mathrm{n}=34(34 \%)$ \\
Von Wahl's set of three & $\mathrm{n}=87(87 \%)$ \\
Dumped of ASP & $\mathrm{n}=100(100 \%)$
\end{tabular}


Table 3. Results in 210 months.

\begin{tabular}{cc}
\hline Results & N Patients \\
\hline Mortality & $14(14 \%)$ \\
Toxic shock with visceral multi-failure & $13(13 \%)$ \\
Pulmonary embolism & $1(1 \%)$ \\
Morbidity & $12(12 \%)$ \\
Surgical site infection & $11(11 \%)$ \\
Evisceration & $1(1 \%)$ \\
\hline
\end{tabular}

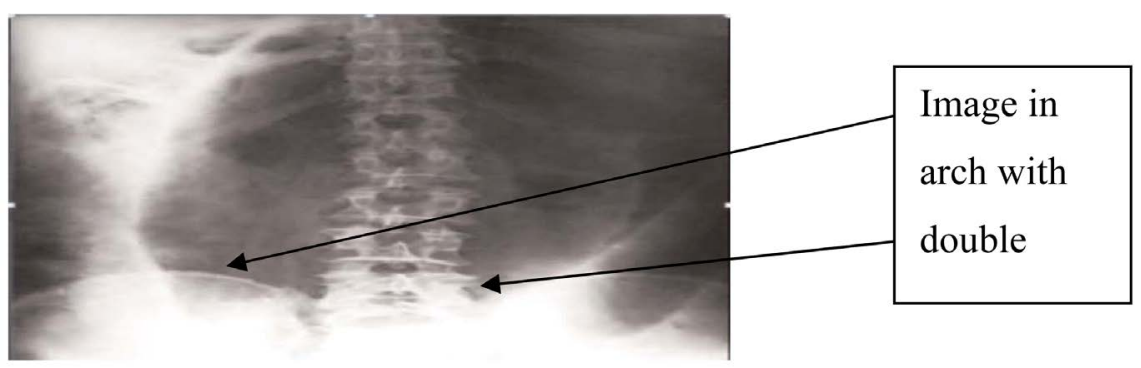

Figure 1. Radiography of the belly without preparation showing an image in arch with double jamb.

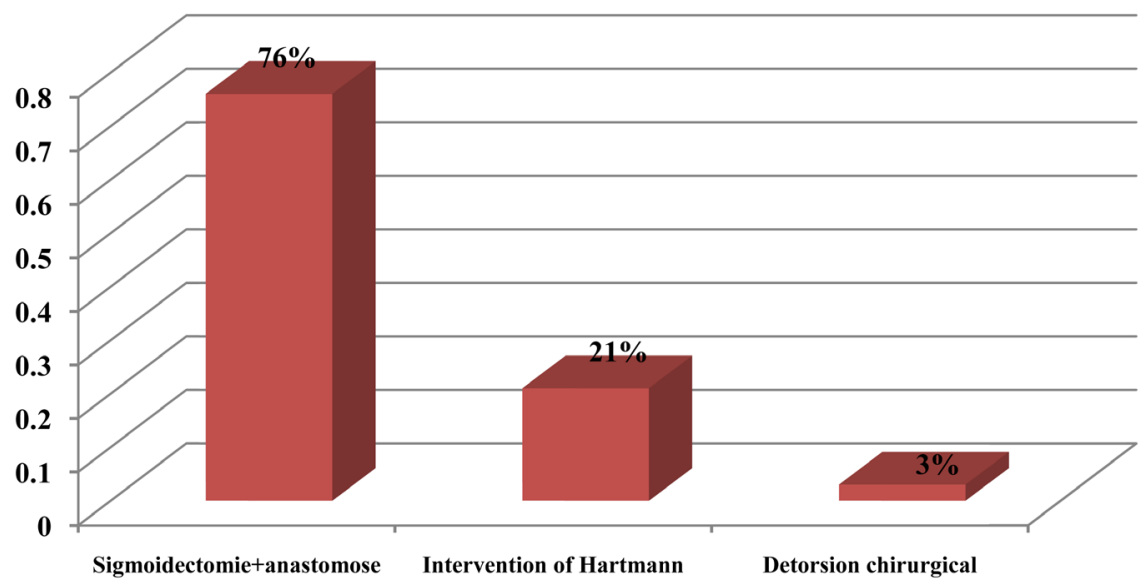

Figure 2. Type of surgery.

All these factors are at the origin of a dolichosigmoid with a long meso on narrow and retracted base, favoring the twisting of the handle sigmoid around its mesenteric axis. VS is rare at the child's [9]; it is at the origin of an intestinal obstruction ague with a fast evolution towards the necrosis of the handle volvulée. Contrary, at the adult, it is often about a sub-acute and progressive board [10] [11]. The clinical symptomatology is dominated by the abdominal pain and the stops of gases and the vomiting see each other at a late stage. In the forms seen late the presence of peritoneal signs translates the necrosis of the handle sigmoid (Figure 3, Figure 4). The radiography of the belly without preparation is an volvulus of the sigmoid by showing a typical image in the form of an arch with double jamb [12]. In our study the ASP was asked at all the sick. It showed 


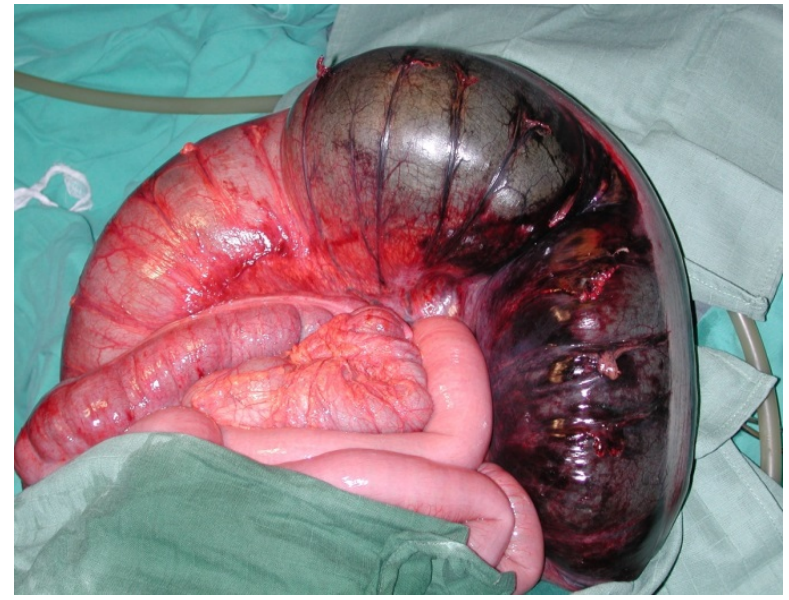

Figure 3. Necrosis of the sigmoid (seen op).

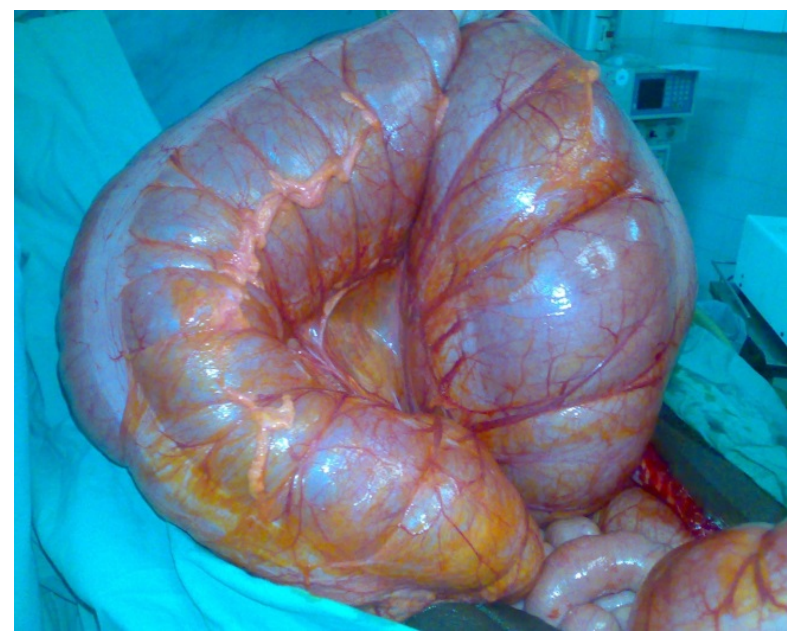

Figure 4. Operating view of a volvulus without necrosis.

an image in double jamb in $65 \%$ of the cases.

But it is the low digestive opacification in the hydrosoluble that gives typical images in beak of bird, in our series, the rectal injection in hydrosoluble was not realized for lack of technical tray. These last years, the scanner became a tool extremely performing in the field of the digestive emergencies. In the case of VS, the scannographic study allows at the same time to make the diagnosis and to reveal possible radiological criteria of gravity [13]. Much upper to the radiography of the belly without preparation and to the opaque rectal injection, the information supplied by the scanner is essential element in the choice of the best adapted therapeutics [14]. The treatment of the volvulus of the sigmoid is in full evolution. The resection of the colonist sigmoid followed by an immediate anastomose countered as the method of choice [8]. This technique is associated with a risk of desertion anastomotic from $1 \%$ to $10 \%$. Certain factors as the anemia, a state of shock or the transfusions died operating are predictive factors of anastomosis desertion, in particular at the patients presenting a colonic necrosis [15]. During our study, it was the most used technique (76\%) at other authors [16] 
[17]. We think as other authors [12] [17], that the resection of the sigmoid as a matter of urgency followed by an immediate anastomose is a sure and effective method if the following conditions are combined: state general voucher, experimented surgeon and if the resuscitation meadow, preoperative and post-operative can be assured.

The endoscopic distortion in the absence of signs of gravity allows crossing an acute course to prepare the colonist and the patient. The rate of failure of the endoscopic devolvulation varies from $10 \%$ to $30 \%$ [18]. During our study, this technique was not used considering the impossibility and the difficulty in our context of exercise to sit an exact preoperative diagnosis of the origin of the occlusion on one hand, and on the other hand to specify the vitality of the handle.

Several preservative processes were proposed for the surgical treatment of VS at the adult, such as the mesosigmoidoplasty, the sigmoidopexie or the mesocoloplasty [19]. These methods give low rates of morbimortality, but are not always possible and come along with a high rate of second offense.

We think as other authors [20] [21], that the resection of the sigmoid as a matter of urgency followed by type Hartmann's stoma or Bouilly-Volkmann is a sure and fast method in case of necrosis. The recovery of continuity is realized in 3 months following the intervention. During our study, she was realized in 21 cases. We had no statistically significant difference between the operating consequences of the operating techniques on the necrosis colons.

\section{Conclusion}

To Mopti, the coverage of the volvulus of the sigmoid is surgical. The endoscopic devolvulation followed by a sigmoid resection during the same hospitalization is not on the agenda in our countered. The resection of the sigmoid as a matter of urgency followed by an immediate anastomosis is the technique of choice in our service if the following conditions are combined: state general voucher, experimented surgeon and if the resuscitation meadow, per and post-operative can be assured.

\section{Conflicts of Interest}

We, authors of this article declare that there is no conflict of interests.

\section{References}

[1] Sule, A.Z., Iya, D., Obekpa, P.O., Ogbonna, B., Momoh, J.T. and Ugwu, B.T. (1999) One-Stage Procedure in the Management of Acute Sigmoid Volvulus. Journal of the Royal College of Surgeons of Edinburgh, 44, 164-166.

[2] Khanna, A.K., Kumar, P. and Khanna, R. (1999) Sigmoid Volvulus: Study from a North Indian Hospital. Diseases of the Colon \& Rectum, 42, 1081-1084. https://doi.org/10.1007/BF02236708

[3] Madiba, T. and Thomson, S. (2002) The Management of Caecal Volvulus. Diseases of the Colon \& Rectum, 45, 264-267. https://doi.org/10.1007/s10350-004-6158-4

[4] Avots-Avotins, K.V. and Waugh, D.E. (1982) Colon Volvulus in the Geriatric Pa- 
tient. Surgical Clinics of North America, 62, 249-260.

https://doi.org/10.1016/S0039-6109(16)42684-8

[5] Assan, A. and Slivanov, I. (2001) Sigmoid Volvulus: Management by Resection and Primary Anastomosis. East and Central African Journal of Surgery, 6, 19-20.

[6] Strom, P.R., Stone, H.H. and Fabian, T.C. (1982) Colonic Atony in Association with Sigmoid Volvulus: Its Role in Recurrence of Obstructive Symptoms. The Southern Medical Journal, 75, 933-936.

[7] Tomita, R., Ikeda, T., Fujisaki, S., Tanjoh, K. and Munakata, K. (2003) Hirschsprung's Disease and Its Allied Disorders in Adults' Histological and Clinical Studies. Hepato-Gastroenterology, 50, 1050-1053.

[8] Sinha, R.S. (1969) A Clinical Appraisal of Volvulus of the Pelvic Colon with Special Reference to Etiology and Treatment. British Journal of Surgery, 56, 838-840. https://doi.org/10.1002/bjs.1800561111

[9] Mimi, N.T., Carrie, R.S., Charles, S. and Philip, G. (2004) Recurrent Sigmoid Volvulus in a Sixteen-Year-Old Boy: Case Report and Review of the Literature. Journal of Pediatric Surgery, 39, 1434-1436. https://doi.org/10.1016/j.jpedsurg.2004.05.021

[10] Hinshaw, D.B. and Carter, R. (1957) Surgical Management of Acute Volvulus of the Sigmoid Colon. Annals of Surgery, 146, 52-60. https://doi.org/10.1097/00000658-195707000-00006

[11] Ton, M.N., Ruzal-Shapiro, C., Stolar, C. and Kazlow, P.G. (2004) Recurrent Sigmoid Volvulus in a Sixteen-Year-Old Boy: Case Report and Review of the Literature. Journal of Pediatric Surgery, 39, 1434-1436. https://doi.org/10.1016/j.jpedsurg.2004.05.021

[12] Diallo, G., Diakité, I., Kanté, L., Togo, A., Traoré, A., Keita, M., et al. (2009) Volvulus du Colon Sigmoide (VS) au Centre Hospitalier Universitaire Gabrile Touré de Bamako. Médecine d'Afrique Noire, 56, 377-381.

[13] Delabrousse, E., et al. (2001) Volvulus du Sigmoïde: Intérêt et Apports de l'Etude Scanographique. Journal de Radiologie, 82, 930-932.

[14] Morrissey, T.B. and Deitch, E.A. (1994) Recurrence of Sigmoid Volvulus after Surgical Intervention. The American Journal of Surgery, 60, 329-331.

[15] Karanjia, N.D., Corder, A.P., Holdsworth, P.J. and Heald, R.J. (1991) Risk of Peritonitis and Fatal Septicemia and the Need to Defunction the Low Anastomosis. British Journal of Surgery, 78, 196-198. https://doi.org/10.1002/bjs.1800780221

[16] Raveenthiran, V. (2004) Restorative Resection of Unprepared Left-Colon in Gangrenous VS. Viable Sigmoid Volvulus. International Journal of Colorectal Disease, 19, 258-263. https://doi.org/10.1007/s00384-003-0536-6

[17] Nuhu, A. and Jah, A. (2010) Acute Sigmoid Volvulus in a West African Population. Annals of African Medicine, 9, 86-90. https://doi.org/10.4103/1596-3519.64747

[18] Mishra, S.B. and Sahoo, K.P. (1986) Primary Resection and Anastomosis for Volvulus of Sigmoid Colon. Journal of Indian Medical Association, 84, 265-268.

[19] Avisar, E., Abramowitz, H.B. and Lernau, O.Z. (1997) Elective Extraperitonealization for Sigmoid Volvulus: An Effective and Safe Alternative. Journal of the American College of Surgeons, 185, 580-583. https://doi.org/10.1016/S1072-7515(97)00126-9

[20] Touré, C.T., Dieng, M., Mbaye, M., Sanou, A., Ngom, G. and Ndiaye, A. (2003) Results of Emergengy Colectomy in the Management of the Colon Volvulus in Dakar Hospital. Annales de Chirurgie, 128, 98-101.

https://doi.org/10.1016/S0003-3944(02)00043-3 
[21] Pakkastie, T.E., Ovaska, J.T., Pekkala, E.S., Luukkonen, P.E. and Jarvinen, H.J. (1997) A Randomised Study of Colostomies in Low Colorectal Anastomoses. European Journal of Surgery, 163, 929-933. 